\title{
Reverse logistics: end-of-life recovery pledge
}

\author{
R.C. Michelini and R.P. Razzoli \\ DIMEC - University of Genova \\ Italy
}

\section{Introduction}

The growth requires wealth creation with less eco-impact. For the wellbeing expansion, the underlying organisations and technologies present shared features, with unifying tools in refit engineering, deployments in products-services and support in extended enterprises. The EU already enacted economic instruments aims at: voluntary agreements, for the onduty conformance management; compulsory regulations, for the recovery targets. The ICT aids play main roles in their support. Moving to lifecycle concern, the knowledge-driven frames are necessary, to make possible assessing the items impact and the natural resources decay. The frames establish on three facts (Michelini \& Razzoli, 2000), (Michelini \& Razzoli, 2004a), (Sakao \& Lindhal, 2009):

- to market products-services, with collaborative aids for clients' support;

- to establish extended enterprises, for point-of-service conformance guarantees;

- to monitor the tangibles yield per unit service, by third-parties certifying bodies.

The frame develops with hierarchical topology (Michelini, 2010), (Michelini \& Razzoli, 2005), (Michelini \& Razzoli, 2008):

- the inner cluster, to link the extended enterprise partners, for product-service delivery;

- the specialised links, to support the point-of-service communication with the buyers;

- the outer selective data channels, for the overseeing bodies, under security protocols.

The common, varying-topology, information set-up is unifying context, sliced into layers, (Aggeri, 1999), (Blumberg, 2004), (Popov \& DeSimone, 1997), (Weizsäcker et al., 1997), with:

- lowest levels (product ideation/ construction), at the extended enterprise inner cluster;

- intermediate levels (product lifecycle), for data management at the clients' satisfaction;

- upper levels (eco-consistency and charges collection), controlled by accredited bodies.

The picture is coherent with a controlled collaborative net, linking extended enterprise to individual clients, so that the supply chain (i.e., the delivered product-service) is monitored by an accredited certifying body, for on-duty conformance assessment, undyingly accessed by governmental agencies (Michelini, 2010), (Michelini \& Razzoli, 2004b).

The outlined agenda is considered by the chapter, chiefly addressing the EU environmental policy in the automotive domain, and suggesting end-of-life vehicle recovery/reclamation duty models, properly adapted to the enacted sustainability targets. The issues are tackled summarising topics, as it follows: 
- the knowledge-driven organisation consistent with the EU enacted recovery reclamation targets, assigned to manufacturers' responsibility under the free-take-back scheme;

- the reverse logistic information flow (exemplified by PMARRLELV simulator), supporting data management by virtual net-organisation with the provider-user-controller links;

- the sample analysis of innovation typical features, to help evaluating the backwardstreams effectiveness by focusing critical aspects for recovery-driven sustainability;

- the example study of basic treatment facilities, where the end-of-life item disassembly is accomplished and the recovery and reclamation data are monitored and certified.

The concluding comments address the links between ecological constraints and economic instruments, and stress on the fundamental role played by the ICT aids, both, as off-process and as on-process enabling tools.

\section{The EU recovery and reclamation goals}

The growth, by ceaselessly replacing tangible goods, built transforming natural resources into waste and pollution, grants benefits to the directly involved consumers, with penalty to third parties and future generations. The consumers side covers the all supply chain: manufacturer and user. The former establishes the product functional properties, choosing materials, specifying operation properties and eco-impact, and providing the construction files for maintenance and dismissal. The latter needs comply the technical and legal regulations, to be allowed to enjoy the purchased items. The industrial revolution has highly widened the manufacture market, by increased process productivity, but has, as well, speeded up the resource decay and the environment downgrading, so that the growth becomes critical. We are, apparently, approaching a bottleneck. Voluntary provisions and mandatory restrictions shall urgently apply, to alleviate or slowing down the world decay. The EU has set ambitious goals and sketched severe policies, based on the manufacturer's responsibility, considering three phases, (EC, 2006):

- within the production: antipollution regulations are issued at manufacturing, and design is promoted by series of advices and warnings (e.g., Eco-design of End-use Equipment, draft proposal directive);

- along the supply chain: the eco-consistency figures, included in the construction file, need to be followed, for conformance-to-use, and the service engineering comes out as valuable opportunity;

- at the product disposal: (mainly) the durables (in future, consumables) fall within the suppliers' responsibility, under the free-take-back scheme, aiming at reverse logistic flow for resource recovery, consistent reclamation and dump avoidance.

The regulation acts look after establishing eco-costs, to be included in all the (tangible) goods, brought to the market. These costs need to cover cleaning up, reclamation and consumption quotas, and correspond to explicit tax (collected through producers/dealers), to refund the supply chain burden.

Recovery is fostered as antidote, having the inherent task of educating the consumers to conservative behaviours. Example mass-produced goods are chosen, such as end-of-life vehicles, ELV, and waste electrical and electronic equipment, WEEE, burdening the replacement market, with high environmental impact. The eco-consistency is ruled through producers' responsibility, by enforceable targets regulations. The ELV case gives clarifying hints to this trend. The 2000/53/EC Directive, enacted the 18.09.2000 (with Member States 
acknowledgement before April 2002), defines the rules to be followed by national acts for vehicles disposal, urging the carmakers for selling cars respectful of legal requests. The Commission integrates the rules by notes, e.g., the 2003/138/EC, to explain standards for materials and parts. Basic aspects are summarised in the Fig. 1. The EU is concerned by end targets, not about how they are fixed. A Guidance Document collects harmonisation hints, to avoid misinterpretation.

- collecting systems for exhausted vehicles and parts need to be established at authorised sites, for treatments, to grant safety and security fitting out, by removing potentially dangerous components;

- withdrawal needs to be performed without charge on the final owners (prescription to be fully enabled from 01.01.2007), but recovery visible-fees are included, as attribute of the product-service delivery;

- manufacturers (and dealers) have technical responsibility of the product lifecycle, end-of-life recovery included, being liable of environment impact and resource consumption, due to design choices;

- users co-responsibility is sanctioned, for voluntary non-conservative behaviours, when critical pieces are damaged, removed or modified, altering the original setting of the supply;

- recovery and reclamation duties ought to be acknowledged, with visibility of reused parts, recycled materials, thermo-exploitation and residuals dumping, to be notified to the European Commission.

Fig. 1. Basic aspects of the EU Directive for ELV recovery

The EU goals are differently transferred into national acts; still, the role of manufacturers is fundamental, to support reverse logistics by product-data management. The governmental authorities ought to analyse the whole supply chain, to distinguish one producer from another, on the forward and backward chain, and to define proper taxing rule, with costs ascribed to consumers, by visible fees collection at the point-of-sale. On these facts, the EU environmental policy is promoting relevant changes, (Dyckhoff et al., 2004), (Larson, 2009), (Schmidt et al., 2005), at least with twofold issues:

- to require lifecycle visibility of forward and backward supply chains, so that product data management and service engineering are inherent parts of actual deliveries, with full transparency of the on-duty and disposal impacts, assessed through certified monitoring and reporting;

- to promote urgent restructuring of the manufacture industry, with competitiveness driven by lifelong product responsibility and joined service/recovery duties, so that the lifecycle design aids become main request, enjoying virtual prototype testing and behaviour simulation.

The relevance of the ICT tools clearly emerges, directly, promoting knowledge-driven industry, indirectly, due to the role played by service engineering along the goods lifecycle and from disposal on. The information intensity offers several facets, (Abe et al., 1999), (Meijer \& DeJong, 2009), (Michelini, 2009), (Michelini \& Razzoli, 2008), (Pertsova, 2008):

- with focus on externalities, stress is in the eco-impact, to acknowledge actual effects of on-duty, for allowed use, after conformance-to-use checks, and of end-of-life goods, for recover (reuse/recycle) and dump lawful operation;

- with focus on internalities, stress is in the enterprise capability to preset the on-duty and dismissal data, with extensive resort to off-process simulation aids and virtual prototype testing.

The complexity and vastness of the information frames are immediately evident. The all supply chains need to be monitored and recorded, explicitly joining suppliers and clients. 
Results shall be reported to national agencies (and notified to European Council officers, which verify their compliance), using proper data handling and vaulting caution, granting citizens privacy and security. For the eco-consistency, the information system, (Dekker et al., 2004), (Freedman \& Jaggi, 2006), (Loeffe, 2009), (Sperling, 2009), should be conceived with two goals:

- to cover the lifelong product-service supply, say, the (tangible and intangible) delivery to a client, granting enjoyment of specified functions, by life-cycle indentures, warranted by deliverers, with return on investment, by factual resort to the scope economy;

- to accomplish monitoring and control of the environmental impact, with result reporting by overseeing third party certified bodies (independent on dealers and purchasers) with access to the supply chain, in view to assess and to record the products lifecycle data.

The two goals are deeply connected, since the users are the beneficiaries, to keep on-duty reliability and eco-conformance, but manufacturers have, in both cases, the responsibility of the overall technicalities, and, if something does not properly fit, the all supply chain becomes defective, and out-of-law the items' use (Schmidt, 2004).

To guarantee the eco-consistency, the information framework lumps together purveyor and buyer, both monitored by independent (accredited) supervisors. The three parties rule is good compromise to enhance competition, to grant privacy and to balance commitment, by fair-trade set-ups. The environment footprint transparency is achieved by recording the actual running conditions of the forward and backward flow , (CEN, 1999), (Kahraman \& Baig, 2009), (Veleva \& Ellenbecker, 1996). Such scheme includes:

- purveyors, covering the all supply-chain data: materials provision, items manufacture, lifecycle up-keeping, backward recovery; the ecological responsibility is dealt with by clustering several firms within a factual alliance of co-operating stakeholders;

- users, purchasing products-services to profit of the delivered functions with reliability figure close to one; the payments include point-of-service conformance certification and the end-of-life take-back, the after tax collection against tangibles' depletion;

- supervisors, assuring third party duties for the today and tomorrow environment and society protection; the certifying bodies report to authorities and follow legal metrology standards, having access to the delivery lifecycle data-bases.

Once the changes of the EU environmental policy are on full effect, the manufacturers responsibility will lead to deeply different entrepreneurial organisations, due to knowledgedriven patterns and linked to computer-based instrumental aids. Recovery is fostered as antidote of the affluent society, with the inherent task of educating consumers, towards more conservative behaviours, (Leavis \& Thompson 1993), (Michelini \& Razzoli, 2004), (Michelini, 2010), (Muñoz, 2009), (O'Neill, 2001), (Uchitelle, 2006).

Broadband actions are chosen, such as the ones dealing with the end-of-life vehicles, ELV, mass-produced goods, typically, feeding the replacement market, with high eco-impact. Conservativeness is achieved through the carmakers' responsibility, setting out regulations with enforceable targets and visible fees, easy to run and control. The mentioned ELV regulation provides explanatory hints. The 2000/53/EC Directive defines the rules to be followed by national organisations for vehicles dismissal, and by automotive producers for trading cars respectful of legal requests. The Commission further modified and integrated the rules by special specifications, e.g. the $2003 / 138$ /EC, to establish standard codes for parts and materials. It needs to be mentioned that the EU is concerned by final issues, not about how these achievements are obtained by Member States. This creates drawbacks to carmakers, 
which ought to comply with uneven interpretations; the Guidance Document is, thus, added, to collect harmonisation hints. The fast growing documentation, (Michelini \& Coiffet, 2010), (Michelini \& Kovàcs, 2002), (Paul, 2006), (Sperling, 2009), leads to a few remarks, such as:

- regulation addresses environment protection, conferring responsibility to the producers;

- design for disassembly, for recovery, for recycle, etc. practices shall become standard job;

- extensive resort to re-manufacturing, to re-use of parts, materials, etc. is rewarded;

- fit aids (modularity, identifying codes, etc.) are given to make dismantling easier, etc.;

- lifecycle monitoring and reporting certify on-duty conformance-to-specification issues;

- not-justified high-impact and non-consistent behaviours are taxed or totally forbidden.

The remarks show that business paradigms changes are fostered, based on new design patterns, with concern on enhanced point-of-service performance and full commitment for withdrawal. The focus on growth sustainability is basic driver. Obviously, it leads to reverse logistics entrepreneurship, with larger role for competitiveness played by actors in the backward cycle. The present study deals with the recovery, reuse and recycle duties, and it specifically addresses topics in end-of-life vehicles, ELV.

Eco-consistency by reverse logistics entrepreneurship does not develop by itself, as the backward chain outcomes do not have explicit purchasers, lacking links of actual needs to them. Then, to separate backward, from forward chain leads to deviating issues, keeping benefit within a set of individuals, but damaging third (and future) ones. The cost/profit ratio is to be assessed balancing the profit of the consumers side (producers and users), against the protection of all people not involved by the specific value chain. In that sense, regulation for the eco-consistency is peremptory task that governments need to undertake, enacting rules to charge the consumers side for environmental impact linked to the whole supply chain, disposal and recovery (EC, 2006) included. The automotive field is of note, with widely spread market of registered items: the falls-off affect large amount of users; the end-of-life vehicles are individually recognised and recorded. Thereafter, the EU approach specifies mandatory charges, by specified bylaws, notably:

- member states shall establish collecting systems for the exhausted vehicles and parts, at authorised sites, where preliminary treatments will grant safety and security fitting out, by removing noxious and harmful parts;

- withdrawal needs to be assured without charge on the final owners (prescription to be fully enabled from 01.01.2007), but included in the product-service delivery, as inherent attribute, to bring out every new car;

- users co-responsibility could be invoked for special non-conservative behaviours: critical pieces are damaged, removed or modified, altering the original setting of the supply;

- the dismantling and destruction course shall be certified, with assessment of recovery parts, re-cycled materials, thermo-recovery and residuals dumping, to be notified to the European Council.

Those scenarios outlined by the EU directives are, chiefly, enacted for pollution remediation. The mandatory targets distinguish: recovery (up to $90-95 \%$, by contrast with dump residues, e.g., as low as 10-5\% in weigh), from reuse (second-hand market, possibly, up to meaningful fractions) and from recycle (secondary materials, replacing raw provisions). The recovery, which establishes on such targets, favours the expansion of materials, rather than energy, market, due to severe limits on landfill dumping (Michelini \& Razzoli, 2004), (Naess, 1989). Anyhow, the EU eco-policy rouses economic and ecologic effects. In the affluent society, the ceaseless replacing of goods was optimal choice, in front of high labour costs; in the thrifty 
society, the conservativeness of recycling is restricted by the energy using up. However, these targets are consistent with minimising the eco-impacts, once linked with regulating harmful/noxious refuses and polluting wastes. The approach, then, highlights the critical nature of the ELV's disassembly process, for removal of dangerous liquids and parts and safety fitting of the whole material flows. As a result, the recovery characterises by, Fig. 2:

- the need of logistic nets, with collecting and transportation aids, storage points, handling and processing stands, and joint information flow, for acquisition and recording;

- the establishment of proper dismantling shops for safe parts withdrawal, and of suitably located shredding facilities, to grind the left-out hulks to tiny pieces;

- the resort to specialised sorting plants, to separate the different metals (ferrous alloys, stainless steels, brass, aluminium alloys, etc.), from glass, plastics, etc.;

- the expansion of used-parts and recycled-materials tracks, once enhanced the design, manufacture and maintenance based on second-hand provisioning practices.

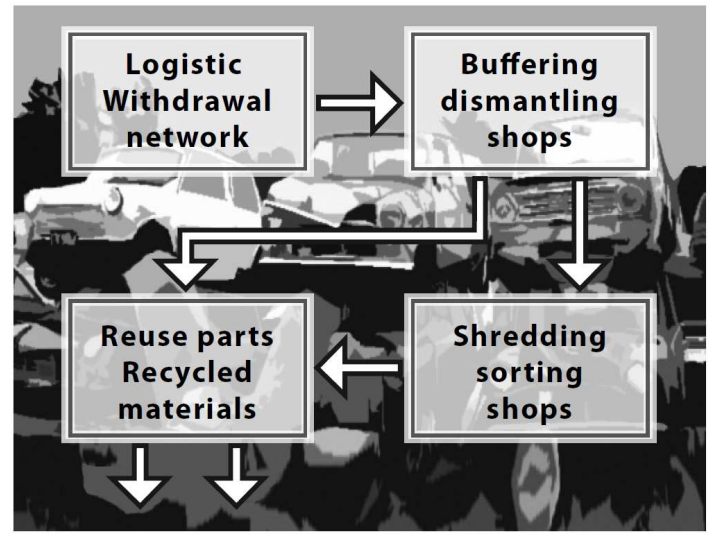

Fig. 2. Reverse logistics material flow

The four processes lead to innovative set-ups: the Authorised Treatment Facilities, ATFs. These work under proper supervision, with full visibility of the achieved issues. From a technical viewpoint, the second and third processes deserve particular interest, with robot aids to be conceived and exploited for irksome and dangerous tasks, today, accomplished by front-end personnel. Besides, the material flow deals with a stream of poor, but large and heavy parts; the handling and dispatching costs could be serious drawback, with high energy consumption. Then, effectiveness would look at distributed processing units and new rigs. Last, but not least, in the backward cycle, the joint information flow bears great relevance, distinguishing (Blumberg, 2004), (Michelini \& Razzoli, 2008):

- the reference knowledge, to make efficient the dismantling, recycling, etc. duties, according to the product data (by means of International Dismantling Information System, etc.), compulsorily provided by the manufacturers;

- the operation flow, with data acquisition, handling, processing and vaulting, to issue the requested records and certificates and to give account of the process compliance;

- the framework assessment, to evaluate competing arrangements and to develop high yield, availability and safety reverse logistics facilities, for enhanced business efficiency. 
All in all, the reverse logistics business is deemed to require effective work-organisations, not less than the traditional forward flow, and the role of disassembly will be central as the one of earlier assembly, unless that, now, the technicalities depend on enforced targets and return on investment is driven by the enacted legal regulations.

\section{The computer simulation tool}

Hereafter, the PMARRLELV code, for reverse logistics simulation, is recalled as investigation tool on the ELV case, to provide introductory explanations. The reverse logistics is the process to design, plan and control the recovery and reuse of worn-out products, in view to preserve natural resources and protect the eco-system. The considered simulation aids develop, exploiting occurrence-driven architectures, to aim at real-time, description of the backward flows, by duplicating the effects of every forcing (and disturbing) inputs, as they take place in the reality. At the same time, alternatives of physical resources and/or logical plans are modelled, making un-expensive virtual tests, without actually building pilot plants. The basic options offered by this kind of simulation aids are well known, and we do not enter into details, (Mihailovich \& Lalic, 2009), (Michelini \& Razzoli, 2009), (Scarpa \& Alberini, 2005), (Wackernagel \& Rees, 1995).

The PMARRLELV code has featuring property to be based on standard packages, Fig. 3, (Acaccia et al., 2006a), (Acaccia et al., 2006b):

- WITNESS tool, version logistics, for the collection-dispatching modules, and version manufacture, for the dismantling-shredding-sorting modules, with virtual reality aids, leading to self-sufficient and friendly modelling.

- MS ACCESS software, standard relational database, released as MS office suite.

- VISUALBASIC.NET, based on the .NET-platform, powerful and flexible, but reasonably friendly also for web applications, assuring management aids to create and to run interfaces with other languages, procedures and databases; to define interactions of blocks; to start/stop concurrent processes; to enable web applications; to establish masks and graphic displays.

- CRYSTAL REPORT XL, as standard to reporting.

That environment aims at providing parametric assessments (Mihailovich \& Lalic, 2009), together showing the causal progress of the physical processes and the heuristic chaining of the decision logic (Michelini et al., 1997), (Michelini et al., 2001), (Michelini et al., 2002). In the present case, the net-frame is further detailed, Fig. 3, to allow reaching further scopes, such as:

- creation of digital mock-ups of actual operation shops, involved in reverse logistics duties, suitably identifying the authorised treatment facilities (ATF) functions;

- provision of personalised access to web-clients (authorities, operators, certifiers, etc.), interested to investigate special outcomes and opportunities;

- build-up of qualified knowledge data-bases, by systematic ranking set of architectures and schedules, permitting comparative appraisals.

The involved physical resources distinguish different operation areas: transportation and dispatching, dismantling and recovering, and, furthermore, shredding and sorting, with local buffers and materials handling rigs. From computer engineering viewpoint, the open network architecture is important feature, due to the multiplicity of involved stakeholders: carmakers, end-users, service providers, certification bodies, etc., all of which have different operation styles 
and interests. The knowledge build-up bears multiple fruits, directly, to acknowledge the behavioural properties of the piece or process under investigation, and indirectly, to re-engineer the whole supply chain (Lapide, 2005), (Michelini, 2010), (Scarpa \& Alberini, 2005), (Stark, 2005).

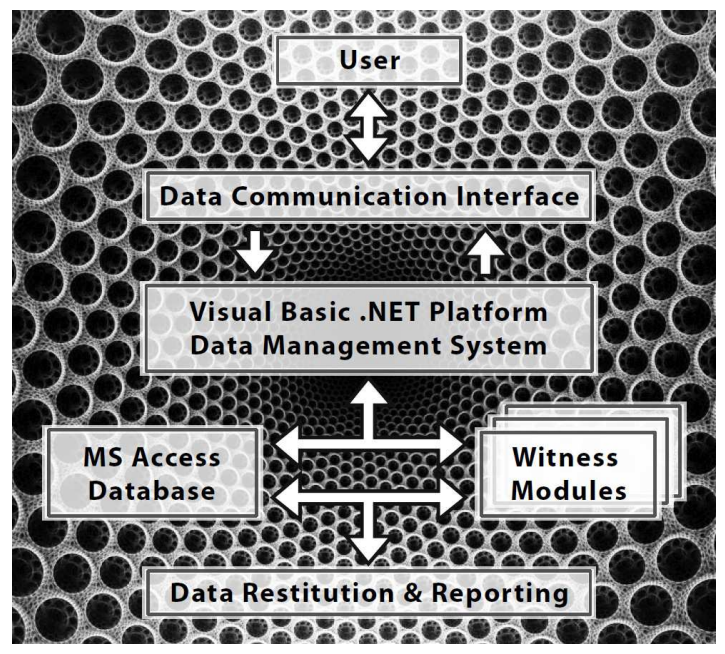

Fig. 3. Block schema of the PMARRLelv code

The shared access to web-clients provides ubiquitous computing and communication, to deal with lifecycle interactivity between stakeholders at different levels of integration, and with multi-task assignments at several involvement requirements and responsibilities. Through the purveyor/user/supervisor scheme, the enterprise boundary blurs into virtual organisation or net concern, linking autonomous (co-operating, conflicting or overseeing) legal entities, to combine core competencies and assemble eco-comprehensive delivery. The virtual organisation leads to dynamic structured partnership, which aims at quick business alignment, when the market changes to deal with externalities (by contrast with earlier carmaking vertical flow-shops) in the environment protection and recycling.

Further sets of involved PMARRLELV web-clients come from government/local authorities, in view to establish the overseeing/control set-ups. Virtuality is assumed to exploit a twin interface, above and under each node, which interposes a broker, hiding the client and/or the server; the operation unit or partner, does not see the real structure: it sees its virtual image, supported by the manager of the interposed relational database. In this way, the (real) knowledge units (in the PMARRLELV) exist, but the web-client works in the virtual space, without interfering with the real units (or blocks of WITNESS architecture). The code needs careful programming, as the .NET-platform specialisation is done (based on standard instructions), to give personal access to the web-clients (by twin-layer interfacing), and to allow agility/flexibility to the dynamic partnerships, as worthy eco-transparency means.

Based on the shortly expounded PMARRLELV structure, the ELV treatment analysis includes four domains (Acaccia et al., 2005) :

- a logistic net, for items collecting and transfer, storage spots, handling and inspection devices, and the joint information flows for data acquisition and recording; 
- adequate dismantling shops for safe parts recovery and storing, with forwarding of the residual hulks to suitably located shredding facilities, for grinding to tiny pieces;

- detailed parts-reuse and materials-recycle tracks, with feedback on maintenance-service aids and on design/manufacture practices with second material provisioning;

- efficient sorting plants, to pull out metals (ferrous alloy, stainless steel, aluminium alloy, brass, etc.), different plastics, glass, etc., and safe incineration plants.

The four domains bore, up today, little overlapping with traditional automotive fields. Only recent EU regulations foster design-for-recovery and enforce end-of-life take-back, so each carmaker can modulate his engagements by voluntary agreements for the lifecycle service, and by explicit obligations for the end-of-life recovery. The three parties scheme binds the producers/sellers, with the clients/users and, both, with the overseeing/certifying agencies. The existing ICT aids make possible apt net concerns, with varying topology lay-outs, so that each partner (an activity-node in the net) is allowed full visibility (through twin-layer interfacing) of every details, as specified by the enacted compulsory eco-rules. The resulting virtual organisation does not correspond to a single industrial company. The simulation needs to duplicate peculiarities and facets of the net concerns, based on factual job-agendas.

\section{Recovery/reclamation information flow}

The PMARRLELV code, as said, aims at assessing the ELV treatments, leading to a set of modules, in order to grant:

- the take-back and gathering of end-of-life vehicles, for lawful disposal treatments;

- the ELV dismantling, with parting of reuse-parts and recycle-materials, from residuals;

- the material recycling processes, after shredding/sorting, and safe landfill dumping;

- the backward-to-forward chain data-flow to exploit conditioning economic instruments.

The code includes the EU enacted mandatory targets, namely:

- from 01.01.2006: $90 \%$ by weigh of the vehicle ought to be recovered or recycled, and only $10 \%$ can be dumped (suitably neutralised) to landfill; in any case, materials recycling should be as high as $85 \%$, since only $5 \%$ can be used as auxiliary fuel;

- from 01.01.2015: the figures are modified, allowing $10 \%$ for fuel use, but only $5 \%$ to landfills (aiming at the recovery figure of $95 \%$ by weigh).

The enforced figures are input set-points, and could be object of revision. Today, the ELV metallic content is consistent with $85 \%$ recycling target, since, generally over than 15 years old car are withdrawn. The plastics content of recent cars is quite higher, and this target becomes difficult. Moreover, the landfill limitation (10\% today, and 5\% from 2015) is quite restrictive, being mainly driven by anti-pollution summons, with no concern on and energy consumption. The eco-soundness should dress overall balances, measuring the results in terms of natural resources decay and modifying the enacted targets, whether the recovery figures bring to higher consumption (and pollution). Of course, these balances highly depend on available technologies. The product (vehicle different design) or process (new forward/backward chains) innovation will open more effective tracks. Setting enforceable targets, together with fixing up the manufacturers' responsibility, will, most likely, promote competition and, thereafter, innovation. At least, this is hoped by the EU, aiming at common market, along fair trade tracks. The PMARRLELV code results help to such purpose.

The knowledge flow transparency is prerequisite of fairness. At the moment, the backward streams bear quite loose operation styles: ELV are fetched at random times and scattered 
locations and dropped to off-hand wrecking shops; disassembly and reuse duties are often done by extempore operators, as case arises; only, shredding and sorting tasks have resort to mechanised plants, still requiring human-intensive attendance. The economic and ecologic efficiencies of the whole are, both, very low, with no interest of the car-makers to bring forth enhanced resource recovery, as this might pull down the sale of new items, till when the free take-back are avoided by unscrupulous manufacturers (and incompetent controllers). The producers responsibility will foster more conservative behaviours, on condition to achieve transparent management of the economic instruments, so that drawbacks and benefits are distributed with objective fairness. This condition, however, is still to come, with involved actors often operating with low visibility.

The PMARRLELV code is especially conceived to carry out analyses on the backward chain, acknowledging the critical steps, so that complete visibility of actually fulfilled processes is quantitatively achieved. The enabling role of the ICT ought to be emphasised, as it assures technology up-grading and systemic innovation for a class of policies based on:

- the resort to manufacturers' responsibility, linked with economic instruments drivers;

- the involvement of stakeholders, with dissimilar technological profile and capability, uneven market position and power, and unlike interest towards sustainability;

- the planning of the mandatory targets achievement, by business paradigm shifts, where the products-services and the extended enterprises (or net-concerns) play critical role.

These three policies apply when the recovery-reuse-recycle targets lead to fixed figures, and compulsory regulations are ratified, with sanctions and fines to infringers. The enacted targets are quite rigorous, but the transparency of the actually obtained results is, by today, largely neglected by most of the EU member states. Noteworthy exception is, perhaps only the Netherlands, within which a steering Foundation grants effective co-operating between, partners, showing that the recovery/reclamation obligations are actually accomplished at comparable low (and decreasing) costs (ARN, 2008).

Elsewhere, the lack of reliable data is impressive. The PMARRLELV code is, thus proposed to help stimulating the consciousness of the problems.

Indeed, the knowledge build-up by simulation is powerful way to assess drawbacks and benefits, and their sharing by the involved stakeholders. Actually, the waste items (from cars, domestic appliances, etc.) quickly reach negative value, in face of all-inclusive recovery (reuse/recycle) targets, due to dismantling and dumping costs higher than the sale prices of reused parts and recycled materials. Then, the pace-wise up-grading, based on voluntary agreements between private partners, is unable to economically achieve the mandatory EU targets with return on investment, thus inter-dependent value-chains shall be pursued (BMW, 2004), (Mayer \& Cohen, 2003). On these facts, the induced off-springs addresses:

- the creation of networks of transporters, collectors, dismantlers, shredders, sorters, etc., with the related links, upwards, to manufacturers and dealers, and downwards, to parts re-users and materials recyclers;

- the analysis of sets of certified bodies, registered by the national authorities and notified to the EU, to accomplish overseeing duties, to record achievements, to draw eco-fees, and, whether the case arises, to inflict the punishments;

- the review of product-service deliveries, with high recovery figures (avoiding dangerous substances or parts, good dismantling properties, modular sub-items, etc.), supported by virtual/extended enterprises, with lifecycle responsibility. 


\begin{tabular}{|c|c|}
\hline \multicolumn{2}{|c|}{ Liguria (2004): } \\
\hline total de-registration: & 1578 \\
\hline collected ELV: & 34052 \\
\hline \multicolumn{2}{|c|}{ District of Genova (2004): } \\
\hline total de-registration: & 21982 \\
\hline collected ELV: & 18284 \\
\hline
\end{tabular}

Table 1. Arrival rate

Separately, the induced off-springs do not have the potential to reach economical profit together with eco-sound targets. Important up-grading might exploit special adjustments (e.g., cascade recycling, say, the resort to secondary materials to increase the tangibles yield per unit service, etc.), but only integrating the options leads to method innovation, say, the industrial setting based on knowledge-driven entrepreneurship.

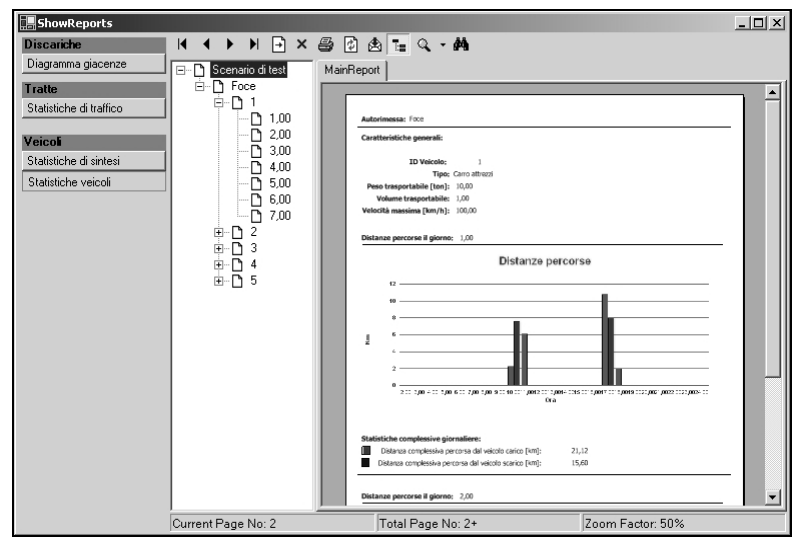

Fig. 4. The PMARRLELV environment example output

As example application, the PMARRLELV environment is used as reference tool for the local authorities of Genova, to establish an effective withdrawal policy for dropped out end-oflife vehicles, whose lawful recovery is not easily traceable. The reclamation tasks are let out to a set of wreckers, required to fetch and bring the left-out vehicles to given store-shops in the town near-outskirts. The problem deals with local issues, Table 1, detailed by:

- the map covered by the withdrawal service;

- the travelled road lay-out, with traffic-periods weigh;

- the duty-service of the selected wreckers;

- the capacity of the temporary store-shops.

The analysis considers several competing lay-outs, changing the wreckers allocation, the duty-cycles, the job priorities, etc.; then, typical performance charts are generated, providing 
synthetic indices (Fig. 4) to show the wreckers utilisation ratio, the average figures of the considered tasks, with specification of the total amount of removed vehicles and nominal properties of each service. The considered issue is direct outcome of the burdensomeness in Italy of de-registration practices, so that the owners of old crocks profit by dropping off their ELV, to by-pass bureaucracy and costs. The local boroughs need to fulfil reclamation duties, with the further constraints to find-out the law infringers and to satisfy the enacted eco-rules. The local biasing conditions are, however, a relevant aspect to understand the actual effects risen by applying the EU directives.

\begin{tabular}{|c|c|}
\hline Set-in-safeness stand: & $\begin{array}{c}\text { ELVs per loading } \\
\text { capacity }\end{array}$ \\
\hline drained fluids: & 231 \\
\hline electrical batteries: & 1448 \\
\hline tyres: & 74 \\
\hline Dismantling/shredding & $\begin{array}{c}\text { ELVs per loading } \\
\text { capacity }\end{array}$ \\
\hline stand: & 746 \\
\hline glasses: & 217 \\
\hline plastics: & 30 \\
\hline ferrous metals: & 202 \\
\hline non-ferrous metals: & \\
\hline
\end{tabular}

Note. The transported materials are considered shredded.

Table 2. Number of ELV necessary to fulfil the loading capacity of a lorry

In the existing surroundings, the application of the PMARRLELV code in the Genova (and Liguria) case, has to deal yearly, see the Tab. 1, with some 20000 (and 40 000) ELV, 20\% of them coming from dropped-off vehicles (more or less, at known locations, Fig. 3). The study considered different competing solutions. The EU directives require to single out the set of Authorised Treatment Facilities, ATFs, which guarantee process monitoring and targets achievements. These are, mainly, storing and dismantling stands, in charge of the safe materials separation for the recovery (reuse, recycle) jobs and the remediation functions. Preliminary assessments show that suited efficacy could be reached with yearly treatment of around 10000 ELV. The figure balances the fetch/transport costs, with the dismantle fees: the higher efficiency of mass-dismantling vanishes due to the higher handling/transport costs of the scattered old crocks. This gives a preliminary guess to chose the number and the location of sound ATFs.

In fact, on the said regional basis, the backward flow fittingly organises, distinguishing the needed transportation, buffering and processing resources. An example arrangement could include temporary buffers, separately: - for the dropped-off ELV, six collection stands: 3 in Genova, 3 in the district (with comparatively long demurrage, for the law requests); - for the ELV withdrawn by the car dealers, twenty collection stands: 10 in Genova, 10 in the district; followed by four ATFs (2 nearby Genova, each one treating around 9150 ELV per year). In order to acknowledge the overall lay-out, the monthly productivity is devised.

Then, with simulation runs of four weeks, some 1524 ELVs need to be treated, and, parcelling out the yearly arrivals over the 48 working weeks (established on 5 work-days and single 8 hours long shift), the two flows need to be considered:

- 1 ELV dropped-off, to be removed on averaged 3 hours rate;

- 1 ELV withdrawn from the car dealers, according to a 2.6 hours rate. 


\begin{tabular}{|c|c|}
\hline Material & Lorries fulfilled \\
\hline drained liquids & 3.59 \\
\hline batteries & 0.57 \\
\hline tyres & 11.23 \\
\hline glasses & 1.11 \\
\hline plastics & 3.83 \\
\hline ferrous metals & 27.70 \\
\hline non-ferrous metals & 4.11 \\
\hline
\end{tabular}

Table 3. Quantities of dismantled materials

The transportation fleet, for the all backwards flow, was established to include:

- haul-away cars, carrying up to six ELV (mainly, from car-dealers);

- break-down vans, mostly, for the fetching of single dropped off ELV;

- motor lorries, for the treated output, handled in containers or as wreck in bulk.

\begin{tabular}{|c|c|c|c|c|c|c|}
\hline N. & $\begin{array}{c}\text { Total In } \\
(\text { ELVs })\end{array}$ & $\begin{array}{c}\text { Max } \\
(\text { ELVs })\end{array}$ & $\begin{array}{c}\text { Now In } \\
(\text { ELVs })\end{array}$ & $\begin{array}{c}\text { Total Out } \\
(\text { ELVs })\end{array}$ & $\begin{array}{c}\text { Avg Size } \\
(\text { ELVs) }\end{array}$ & $\begin{array}{c}\text { Avg Time } \\
\text { (min) }\end{array}$ \\
\hline 1 & 62 & 6 & 2 & 60 & 3.05 & 1419.51 \\
\hline 2 & 63 & 1 & 0 & 63 & 0.41 & 186.46 \\
\hline 3 & 63 & 6 & 3 & 60 & 2.40 & 1100.64 \\
\hline 4 & 60 & 6 & 6 & 54 & 2.83 & 1360.98 \\
\hline 5 & 62 & 1 & 0 & 62 & 0.24 & 110.38 \\
\hline 6 & 60 & 7 & 0 & 60 & 2.75 & 1322.66 \\
\hline 7 & 60 & 7 & 6 & 54 & 3.33 & 1601.74 \\
\hline 8 & 61 & 1 & 1 & 60 & 0.49 & 234.07 \\
\hline 9 & 63 & 1 & 1 & 62 & 0.56 & 258.78 \\
\hline 10 & 62 & 7 & 2 & 60 & 3.69 & 1720.18 \\
\hline 11 & 65 & 2 & 1 & 64 & 0.69 & 305.38 \\
\hline 12 & 61 & 8 & 1 & 60 & 2.82 & 1337.66 \\
\hline 13 & 61 & 8 & 1 & 60 & 4.07 & 1929.24 \\
\hline 14 & 61 & 2 & 0 & 61 & 0.68 & 321.38 \\
\hline 15 & 60 & 8 & 6 & 54 & 3.52 & 1695.74 \\
\hline 16 & 59 & 2 & 1 & 58 & 0.33 & 162.07 \\
\hline 17 & 62 & 6 & 2 & 60 & 2.81 & 1310.33 \\
\hline 18 & 62 & 2 & 1 & 61 & 0.59 & 275.36 \\
\hline 19 & 60 & 7 & 6 & 54 & 3.48 & 1675.43 \\
\hline 20 & 61 & 2 & 1 & 60 & 0.85 & 404.41 \\
\hline 21 & 61 & 7 & 1 & 60 & 2.94 & 1393.42 \\
\hline 22 & 61 & 7 & 1 & 60 & 3.41 & 1614.04 \\
\hline 23 & 62 & 7 & 7 & 55 & 3.21 & 1496.41 \\
\hline 24 & 60 & 8 & 7 & 53 & 3.56 & 1715.86 \\
\hline 25 & 61 & 6 & 1 & 60 & 2.25 & 1067.67 \\
\hline 26 & 61 & 7 & 7 & 54 & 3.34 & 1584.10 \\
\hline & 1594 & 5.08 & 2.50 & 1529 & 2.24 & 1061.69 \\
\hline
\end{tabular}

Table 4. Collection stands statistics

By simulation, several reverse logistics policies are compared. An example policy aims at concentrating in the local ATFs self-consistent recovery steps, to handle in output sets of containers, with diversified contents. Then, the reference figure addresses the number of 
ELV necessary to fulfil the loading capacity of a lorry, by standard 20 feet containers, Tab. 2, for the considered kind of removed pieces, Tab. 3.

The investigation, from then on, provides quantitative figures, depending on the selected operation scenarios, for the temporary allocated resources. Considering, for instance, 20 working-days long (4 weeks) simulation runs, the total amount of ELVs treated by a local facility reaches 831 units. Based on the yearly amount of ELVs, the averaged quantities of dismantled materials listed by Tab. 4 are found, for the Liguria case (six collection stands for the dropped-off vehicles and twenty for the car-dealers withdrawals).

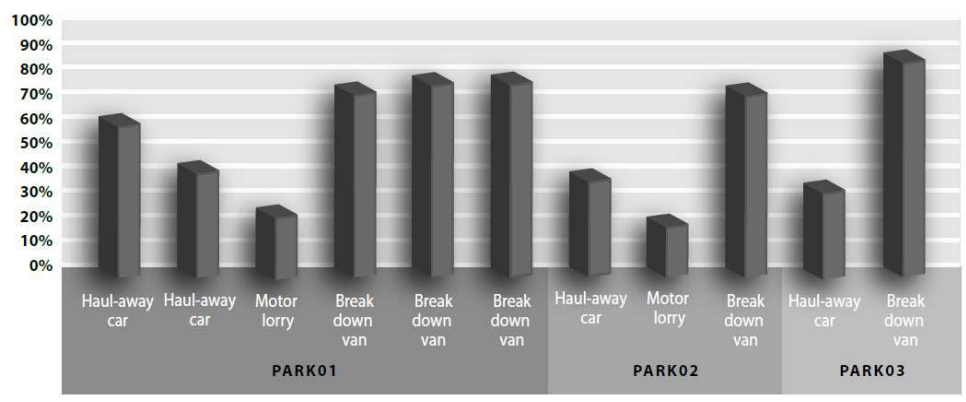

Fig. 5. Backward logistics fleet utilization ratio

The PMARRLELV code allows showing the performance figures of the engaged resources. As example results, the Fig. 5 gives of the transportation fleet: 4 haul-away cars, 5 break-down vans, and 2 motor lorries; the Fig. 6 shows the number of containers fulfilled by the two ATFs operating in Genova, with detailed specification of the carried parts or materials. The transported materials are considered shredded, assuming that the required machinery is locally available, to optimise the transfer/handling costs.

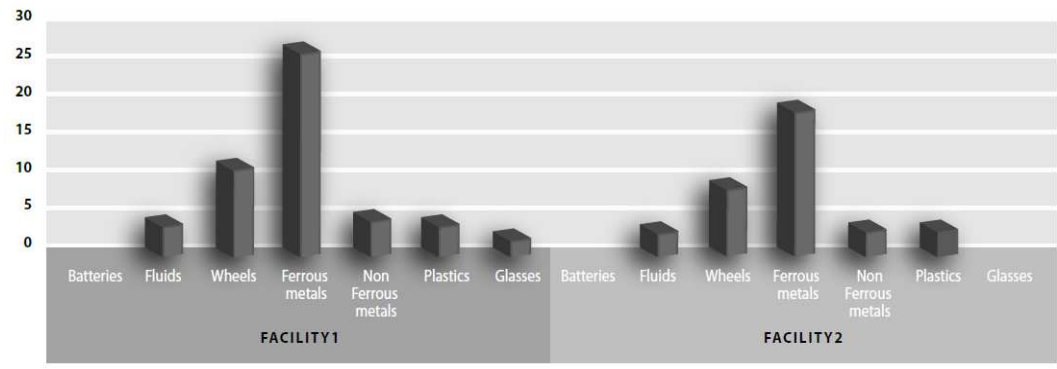

Fig. 6. Number of fulfilled lorries

The Fig. 7 displays the utilisation ratios of the said ATFs, separately specifying the pretreatment (to reach safeness) and the dismantling (for selective withdrawal) stands. The sample results correspond to suitable performance operation conditions, with account of the unexpected occurrences (resources unavailability for break-down, traffic jamming, etc.) randomly generated by the simulator. The Liguria case investigation compared several logistic lay-outs and different resource allocations and distributions, each time providing quantitative assessments of the actually achieved performance. 


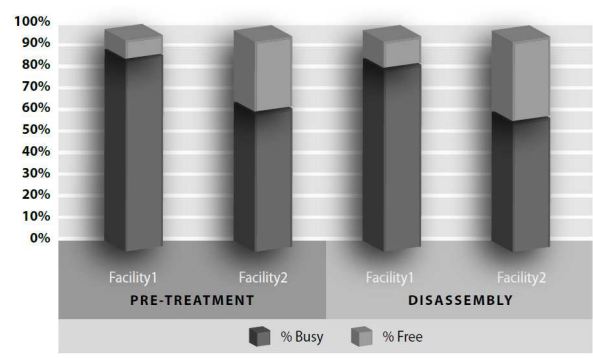

Fig. 7. Treatment facilities utilization ratio

The PMARRLELV code makes easy obtaining detailed results, such as the ones exemplified, and drawing general conclusions, based on repeated simulation runs. In this study, the attention is especially focused on the switching from the voluntary agreements approach, to the compulsory targets policy, to understand the drawbacks and advantages in terms of combined economic and ecologic burdens and fostered innovation vision. To such purpose, the simulation study allows quantitative forecasts. Explanatory hints are also summarised as concluding comments.

\section{Pre-treatment and dismantling shop}

Developing effective car dismantling and recycling facilities is challenge in the carmakers field, with, probably, the most demanding innovations on the automotive field to overcome the world-wide competition. Several investigation lines have been undertaken these recent years, (Paul, 2006), aiming at:

- quantitative assessment of recovery/reuse/recycle processes, under different operation plans, for existing situations (vehicles not produced with recovery mind) and alternative organisations and technologies;

- establishing appropriate recommendations and warnings to improve (by design-fordismantling, DfD, design-for-recovering, DfR, etc., practices), the future, more ecoconservative, automotive market;

- balancing forward and backward chain operations, to optimise return on investment of the manufacture business, based on lifecycle contracts, driven by voluntary agreements and compulsory targets;

- reconsidering the reverse logistics as mandatory requirement for growth sustainability, in front of natural resources ceaseless depletion and human surroundings progressive pollution.

These points are shared by many end-of-life goods, today, massively dumped to landfills. The connection of their backward flows could, possibly, improve, by economy of scale, the logistic flows (collection, transport, storing, etc.) and given steps of recycling (shredding, dispatching, sorting, etc); the effectiveness, however, is highly dependent on the knowledge streams, and, more specifically on the information linked to the material streams, when the individual product is conceived. The fact, is most likely to increase, as the design of new items will start keeping the reverse logistics in mind: this means including the product-data 
management, PDM, in the construction files, for efficient recovery/reclamation, so that oriented programming and equipment are used for enhanced effectiveness.

The investigation and performance assessment of the dismantling facilities, Fig. 8, will, thereafter, become standard routine. The well-established approach, for shop-floor selection, goes across implementing suitable software aids, to describe the equipment behaviour and simulate actual operation achievements. The process physical model shall, first, move from defining work-cycles and work-stations. Indeed: to dismantle means to take to pieces an artefact, or to strip/deprive of its outfits; while: to disassemble, means to systematically separate an artefact into its constitutive parts. Efficiency would lead to prefer the second process. Then, the disassembly process should consider different features: - manual vs. automatic (also: mixed mode operation); - partial (a subset of parts are not removed), selective (a set of parts are removed the first); - parallel (two or more parts are jointly removed), sequential (parts are removed one by one); - non destructive (unbroken parts are withdrawn) vs. destructive (parts are cut/broken during removal); - and so on.
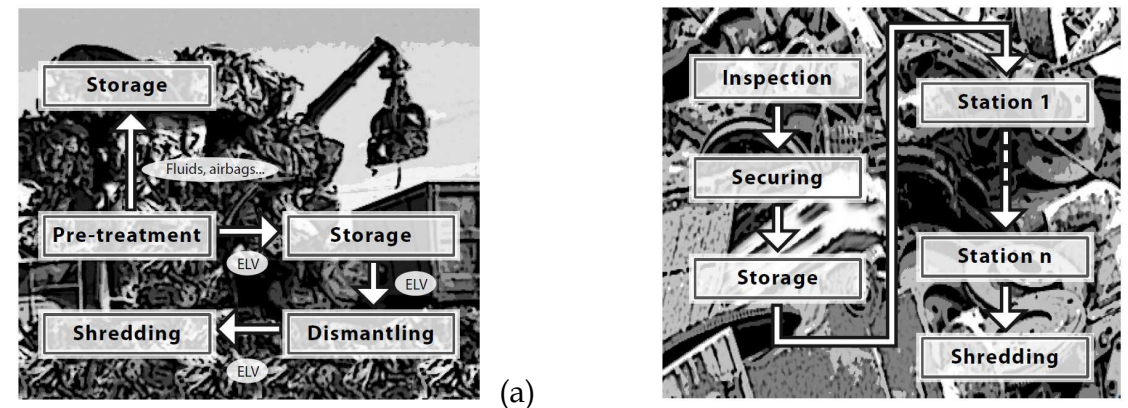

Fig. 8. Dismantling shop: operation lay-out, and dismantling process (a); operation flow (b)

Today, basic knowledge of car-wreckers, Fig. 9, comes from IDIS, International Dismantling Information System, http://www.idis2.com, a data-base of some 1000 vehicle types of 25 carmakers, listing about 46000 pieces. This helps displaying the part solid models and describing texts (in 21 languages), with instructions and tool/fixture requirements.

For environmental protection, the enacted regulations require special care to handle hazardous materials and to safely avoid contamination. This leads to preliminary ELV treatments, to remove potentially harmful or noxious parts (containing lead, mercury, etc.), fluids (for brakes, lubrication, conditioning, etc.), or items (air-bags, exhaust silencer, etc.), etc., which are subject of special restrictions. The subsequent steps address the disassemblyfor-reuse, looking after separating pieces to be restored or remanufactured for second-hand marketing; for competitiveness, the safety and reliability figures need comply suitably high standards. At this stage only, the dismantling-for-recycle should start. The process sequencing aims at clearly separating items into homogeneous blocks as for material properties and recovery potentials, namely:

- outer outfits and glasses (windscreen, window-panes, etc.), for special purpose recovery;

- special pieces (doors, front/rear bonnet, ..) and groups (gearbox, engine, ...), for recovery;

- plastic parts, possibly, ordered according to preselected identifiers or included markers;

- internal outfits/fabrics (covers, upholstery, stuffing, ...), following scheduled plans; 
- metallic parts, possibly, keeping (or re-establishing) the ordering trim of the data-base;

- residual crock-skeleton/wreck, for the subsequent compacting/shredding operations.
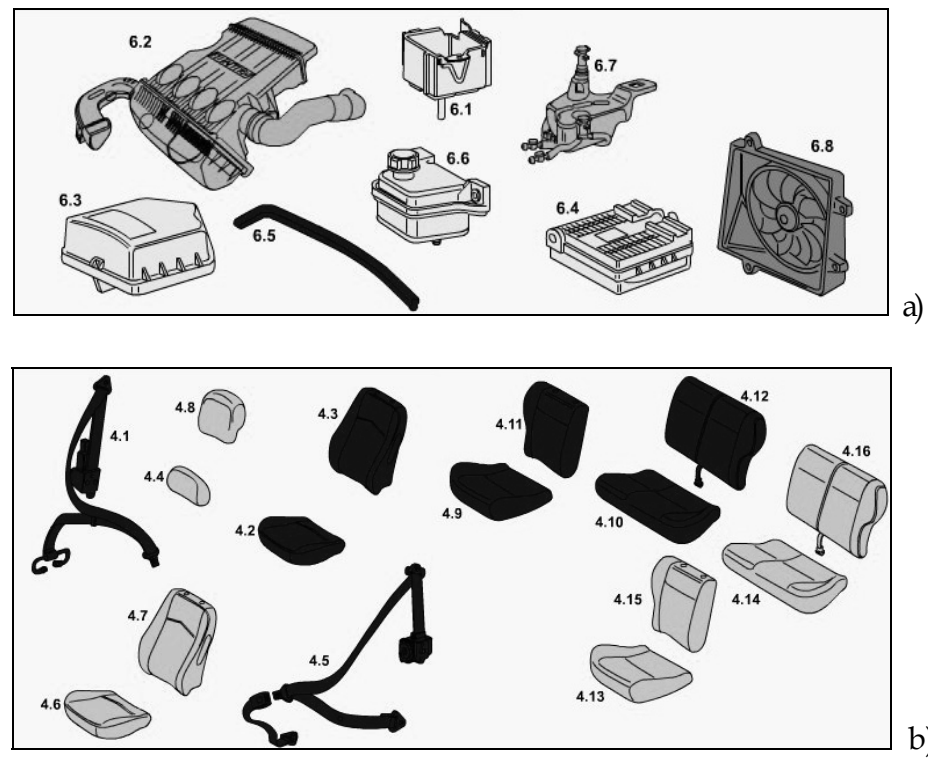

Fig. 9. IDIS db: example engine components (a); example upholstering and stuffing (b)

The detailed description of the work-cycles and accurate development of structured models are basic premise for choosing the plant and assessing the usefulness of robotic aids.

The state of the art is fast evolving, with example plants and prototypal facilities with different levels of sophistication. The Canadian AADCO line, http://www.aadco.ca/, for instance, is useful choice, when productivity is special request, or the German ADEMA system, http://www.lsd-gmbh.com, is valuable support, when leanness and flexibility are primary objectives. Basically, the on-progress trends look after modularity, with series of automatic units (fluids draining, wheels removal, rim/tyre separation, ELV lifting or overturn, gearbox/engine pulling out, etc.), and general purpose handling and transport equipment, between the work-stands. This, quite commonly, leads to mixed-mode flows, with interposed human operators and robotic devices, as, typically, subsets of duties require careful decision-making (e.g., selective handling of hazardous materials, quality figures of reusable components, etc.) and automatic processing would result unreliable, at least, at the present state of the art. The functional modelling of the disassemble/ dismantle line, thereafter, ought to deal with hybrid algorithmic/procedural knowledge frames, which include causal blocks, to duplicate the physical transformations, and heuristic blocks, to emulate the behavioural counterparts. The obtained models directly yield to expert simulation, providing powerful means to experiment on virtual plants, during the facility design, or to compare virtual process-plans, for the on-duty operation, Fig. 8.

The modelling and simulation studies can be undertaken at different deepness of details, from the bird-eye view of the preliminary assessments, to actual feasibility checks of the 
overall reverse logistics schemes and the selection of the individual Authorised Treatment Facilities arrangements.

For the automotive domain, the investigation lines start by the quantitative assessment of the recover/reuse/recycle processes, to comply the mandatory thresholds of the directives. The market size is impressive, with 225 million vehicles (185 million cars) circulating, in 2001, in the original 15 EU Countries and, each year, 10 million cars, moved to landfills. The regulations affect national Governments, and fair transpositions are required, to not bias the common market. Thus, national, regional and local set-outs should be devised, properly tailored to current needs and entrepreneurship qualification.

The Italian case shall face, for instance, some 2 million ELV per year. Notably, around 20000 ELV each year, are processed in Liguria. The eco-bylaws are ruled on the regional scale, but, of course, other collection/processing settings could develop, should be achieved higher return on investment. Today, the car-wreckers represent quite distributed realities, with tiny processing abilities, scarcely complying the eco-protection requests. At the same time, overall inverse logistics networks are far to have reached fully operational deployment, as for carmakers side, as for official monitoring. The law, DL 24.06.2003, suitably transposes the 2000/53/CE directive, but factual specifications still lack, with, e.g., the free-take-back even burdened by severe de-registration fees and loose carmakers interpretations. Last, but not least, the regional and local authorities, most of the time, seem to do not entirely realise the technical relevance of the overall incumbents and related business, primarily interested to bureaucratic accomplishments.

The recovery/reclamation processes, rather than academic study, are urgent necessity, with fully specified legal (directive mandatory rules) and technical (available dismantle/recycle equipment) constraints. Difficulties, due to lack of profitable markets for reverse logistics outcomes, are got over, by combining pertinent economic instruments, namely, free-takeback and visible fees management on the all artefacts lifecycle. This means: - careful effectiveness assessment of actual solutions, as decision aid for the organisational choice and setting; - full transparency of forward and backward supply chain, with optimal allocation of the visible fees, to enhance the national/regional/local competitiveness. Occurrencedriven expert-simulation provides both the scopes: as off-process tool, at the design stage; as on-process support, at lifelong operation. On these premises, the PMARRLELV environment has been considered to simulate the ELV reverse logistics (Acaccia et al., 2006a). Basically, it addresses problems in automotive systems, for withdrawal, collection and dismantling endof-life vehicles, and for shredding, sorting and dispatching the residuals; it is based on the WITNESS language, and incorporates modules for the interactive remote-inquiry, intelligent data-vaulting, and text/graphic restitution, to insert the pertinent data describing the processed ELV, and related components details, Fig. 9.

For explanatory purpose, an example application, focused on ELV dismantling, is discussed. The Liguria case is taken in consideration, singularly and in relation to broader national set-ups. Generally, wastes (and, with full evidence ELV) are bulky, potentially dangerous and very poor materials, thus, every added cost in handling and transportation will lower the process effectiveness. This suggests to localise the dismantling shops on the territory, possibly, with reusing/recycling flows linked to decentralised end-users. Modular lay-outs, based on the ADEMA concept, are arranged, distinguishing separate stands (safety fitting, disassembly for reuse, dismantling for recycle), the transport and manipulation devices and the auxiliary storages (line-buffers and parts collectors). A reasonable setting 
deals with local facilities conceived to process 10000 ELV per years, roughly leading to five lines in Liguria (200 in Italy), according to the expected market.

The example details referred to the Liguria, especially the Genova case is retained. Looking at specific ATFs, Fig. 10, we distinguish between the two phases because the first one has mandatory constraints issued by the EU Directive, thus we have a list of operations to fulfil without optimisation possibilities. Actually, the pre-treatment needs to be done where cars, coming from the road, are collected, while the dismantling can be delayed, after transportation of the wrecks to a different location. The transfer and handling costs of heavy and bulky stuffs are quickly increasing, and the investigation is carried, combining both the functional stands in the same location. In the pre-treatment zone, the ELV are put in nondangerous conditions (for workers and for environment); the work-stations are: inspection, drainage of fluids, removal of dangerous pieces. The withdrawn materials follow prescribed flows, to grant the safety and recovery targets. In the dismantling zone, the ELV are disassembled by selective pick-up or destructive shearing, with logics given by recovery technologies and reuse/recycle opportunities. The obtained parts follow two paths: the reuse path, after reconditioning and remanufacturing; the recycling path, through shredding, sorting, etc. processes.

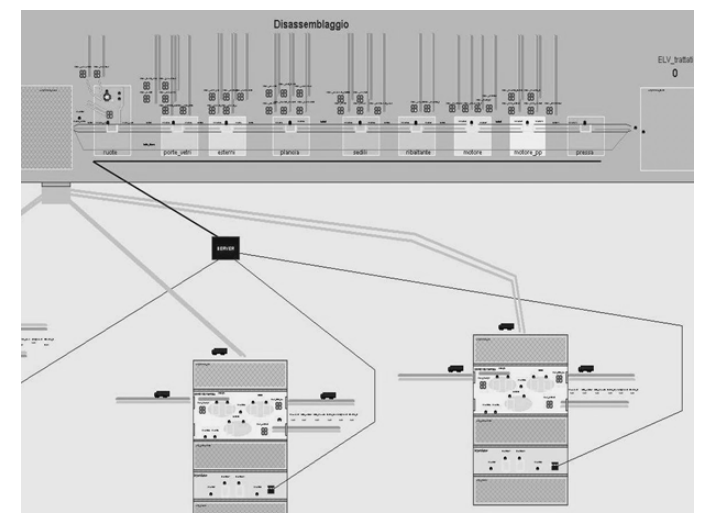

Fig. 10. Pre-treatment and disassembly plants

The ATF dismantles all what is required for safeness requirements, is convenient to recover or reuse, or shall be moved for recycling, up to reach the residual amounts for lawful landfilling. Parameters like accessibility, weight, materials have a great impact at this stage. The main transport system (for ELVs) is a trolley, one in-line, which brings the ELVs through the all the work-stands. The work-stands organize to aim at optimal material collection. Two workers, several containers and internal transports are assigned to every cell. Above all, non metallic materials (glass, plastics, etc.) and reusing components (engines, etc.) distinguish. At the end of the dismantling process, the ELV wrecks shredding or packing (according to logistic requirements) stands are located. The dismantling facility technical data cover: space requests (to store, process, etc. ); material flow (internal transport, handling, etc.); process resources (technologies, workers, etc.); production agenda (ELV technical data: weighs, quantities, materials, tasks, times, etc.). 
Further to the technical specifications, the legal constraints play relevant roles. In Italy, the ELVs follow a legal deregistration line (with payment of official charges), either come out from the unlawful line of dropped out vehicle wrecks. With the latter line, the fees and charges, unless the final user is found, are covered by town local bodies. Thus, the dropped aside wrecks are, generally, stored before processing at the ATFs for a considerable time, to check and to indict the end owners.

The simulation runs considered different feeding scenarios, referred to daily, weekly and monthly agendas, with due parameters setting and alternative end-users flows. The data entry exploits a suitably structured input (every parameter listed in the sheet corresponds to an attribute in the WITNESS coding). The facility operation assume work conditions on shifts base, distinguishing the warming-up and the steady-state running; the normal set-up uses a single daily shift of 8 hours; the exceptional duty could cover up to three shifts. To set the simulation, main data are: the facility data (space requirements, internal transports, etc.); data about operations to be fulfilled and available technologies; the ELVs and their components data (it is necessary to study ELV components to select the items to dismantle, with the pertinent parameters values: weigh, materials, quantities, work-cycles, etc.). The items data require careful assessments; e.g., "time schedules" are manuals with nominal maintenance times, including non destructive dismantling times: scaling factors are needed, to obtain reasonable results from simulation. A time for maintenance, as it appears in a timer manual, is called "assigned" and is the result of this expression that weigh the direct (required to complete the job) and the indirect (required to prepare ELV and fixtures for the job to be done) times; their adaptation for the dismantling tasks, requires a trimming factor, still object of assessments. By simulation, important hints are obtained on the critical nature of competing work-cycles.
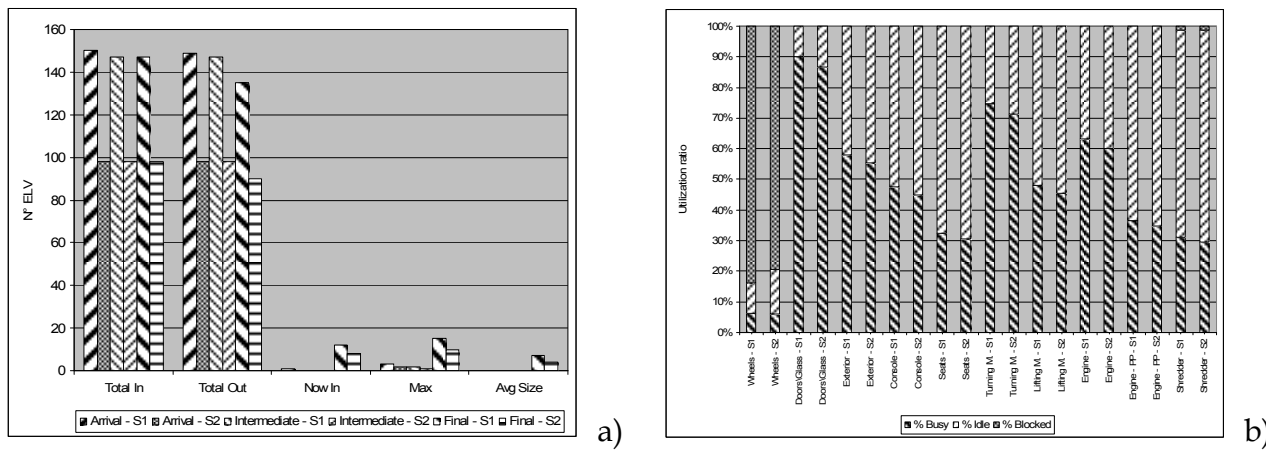

Fig. 11. Pre-treatment buffers statistics (a); disassembly stations utilization ratio (b)

The mixed mode automation is evaluated, with different labours (on-line personnel) or duty-oriented robots. The visualisation avails of animated displays, Fig. 10, where the resources bear clear graphical presentation. On-progress schedules include discontinuities (failures, supply stops, etc.) by occurrence management. The sample outputs, (Fig. 11a-b), show benefits and drawbacks of the case-investigation of decentralised lay-outs, and provide reference hints to acknowledge the main operation details of actual solutions by the WITNESS modules. The performance figures and process statistics are shown as decision aid support. The sample issues refer to simulation runs with warm-up time of about 2000 
minutes (to show how this affects the steady state performance, in the case of interrupted duties): the figure is due to the simulation start time (which is at 12 p.m., on a 3 shifts/day base, possibly, only partially enabled), thus, in the pre-treatment zones, this correspond to more than a 1 week time (with $9 \mathrm{ELV} /$ hour entering the simulation, after 2000 minutes we have $84 \mathrm{ELV}$ entered). The example diagram of the Fig. 11a shows a typical steady state flow giving the stand input/output, with timely work-in-progress and statistical figures; in the Fig. 11b, the utilisation ratio of the processing units are plotted, distinguishing the type of the withdrawal in the dismantling stand, each time giving the busy (on an ELV), the idle (no ELV) and the block (for queuing or other external reason) state.

The concept, behind spreading on the territory local dismantling shops, leads to establish synergies in the reverse logistics of the different durables/consumables covered by the EU mandatory take-back policy. The study shows the sample ATF settlement, highly dependent on the case example, where the carmakers' responsibility is still too much thwarted by carrecycling aids, offered by governments to support the carmakers.

\section{Example remarks}

The role of the manufacturers is fundamental to support reverse logistics by product-data management aids for enhanced dismantling and selective recycling, and turns to be critical, in the short time, to enable design-for-recycling paradigms (e.g., modularity and material segregation, disassembly pre-setting, etc.) and to profit of sustainable manufacture (high resort to recovered or recycled provisions, etc.) and maintenance (proactive up-keeping, re-integration, etc.) options. Besides, governmental authorities need to analyse the whole supply chains, which distinguish one producer from another, suitably defining pertinent taxing rule. The costing will be ascribed to the consumers side, with tax collection duty, mainly, put in charge by the goods sellers, at the point-of-sale. The availability of local multi-task dismantling shops, capable of taking charge of the different backward chains and feeding the subsequent shredding, sorting and dispatching flows, becomes opportunity for enhanced eco-conservativeness.

The connection between backward chains has relevant falls-out. The complexity of problems needs not hinder the obligation that sustainability shall be put directly in charge to the parties having benefits, and not poured on unrelated peoples, if the impact on the environment ought to be kept under acceptable limits. The present EU policy is, certainly, at a very early stage; the enacted bylaws, however, already aim at:

- acting on the consumers (producers+users) side, to foster a thrifty society, instead of a throw-away economy;

- re-orienting the supplier side, to offer functions, instead of goods, for satisfying current needs, without individual ownership;

- establishing positive acts (not series of vetoes that simply give rise to hidden bargains), to empower service economy by fair trade rules, respectful of welfare ecologic side;

- stimulating the jobs for the reuse of tangibles (reverse logistic: to collect, disassemble, recover, sort, sell, etc., second-hand materials);

- supporting knowledge-driven infrastructures, while discouraging the processes with intensive tangibles spoilage;

- fostering common practices the common market over, to look after world-wide covering. The effectiveness assessment and operation transparency are, once again, shared incentive: these allow checks of return on investment and on eco-targets achievement. The simulation 
environments are powerful means, to study useful synergies, suggesting actually enabling options. The end-of-life vehicle ELV case has simple knowledge transparency The waste electrical and electronic equipment WEEE case, already in force by mid 2005, is partially different, as it deals with non-registered goods. Without giving details, producers/dealers, again, are required for items call-back, collection and reclaiming. The recovery and recycle targets apply, depending on appliances size and lighting rigs. The visible fees are collected when new devices are sold. The EU prescriptions are differently transferred into national acts, and some country is considering transient alternatives for some legal (data registration and vaulting, etc.) and technical (withdrawal, dismantling, recycling, dumping, etc.) duties. The two chosen EU cases deal with (chiefly, high quality) durables. The visible fees collection aims at linking the forward and backward tracks, uniformly spreading the extra costs, with balanced effects, and unbiased market deployment, because of economic instruments giving apt support to the chosen EU environmental policy.

These economic instruments attract increasing research attention. Industrial innovation is main answer; still, how the specific measures affect the changes, mostly, address "induced off-springs" and "evolutionary up-grading", while eco-sustainability requests complete paradigm shifts in the growth methods. By now, many projects consider technologic and organisation issues linked to given areas (automotive, electrical/electronic equipment, etc.) once regulations are enacted, and the enterprises' strategies follow the black-box approach, acknowledging the input-output flows and experiencing sample on-the-path adjustments. This way, typically, exploits flexibility and leanness by pace-wise betterments, leaving aside the method innovation, which only will lead to competitive divide in business paradigms. Then, to move a step onward, the black-box research projects ought to operate an integrated approach, joining technical and legal drivers into balanced promotions, with properly wideranging actions. These paths shall encompass (Michelini\& Razzoli, 2000), (Michelini \& Razzoli, 2005):

- process innovation: resource-recovery path, with higher value in part-reuse and material-recycling; thermo-enhancement path, by energy recovery from waste; fullsubstitution path, by modified material choice and items design for high recovering; etc.;

- method innovation: extended artefact path, through commodities and utilities joint delivery; extended enterprise path, through efficient supporting nets; information valueadded path, to replace materials by intangible equivalent-functions; etc.

The choice of the dominant innovation path is questionable subject. The process innovation follows smooth up-grading, due to cumulated knowledge from R\&D projects or empirical tests. The method innovation moves from dissimilar national contexts (some countries have carmakers, some not; sometimes shredding facilities are combined with steel production plants; chemical factories can foster plastic recycling; etc.); etc.; moreover, the expected cost/benefit ratios do not depend only on technical choices; they include wide amount of bureaucracy and governmental biases, forcing the pursuit of one or more tracks, not steered by consistent rules. This means that, in front of the same recovery/remediation compulsory targets in the EU area, largely different cost/benefit issues appear, penalising less efficient structures, with high local charges or low work productivity. The EU will, possibly, not suffer as a whole; the final outcome being to transfer industrial and economic activities from one country to another one, as, in the average, the expected eco-conservativeness will be achieved, with, of course, outcomes in wealth distribution across the common market, (Morin, 1999), (Suhas, 2001). 
The PMARRLELV code helps providing visibility of the conditioning knowledge bases, addressing noteworthy aspects. Example issues are:

- for process innovation: the logistics costs (handling and transport of very poor items) as compared with recovery (reuse, recycle) processing; this knowledge helps to localise the dismantling sites and to establish treatment chains, selectively addressing given goods (WEEE, ELV, etc.), either mixing material refuses, for scale economy;

- for method innovation: the value chain of service engineering supply, covering, out of the mandatory take-back, the whole eco-consistent operation life, to exploit synergic value-added options; this knowledge will help organising the materials and information flows, setting transparency requisites, in view of balancing return on investment and (law-driven) fair-trade constraints (and costs).

Indeed, eco-innovation follows alternative/complementary paths, with interrelated links, exploring technical and legislation drivers to achieve demanding targets and economical profit, with visible outcomes within the different EU partners, as shown by the noteworthy aspects. Other example issues could be mentioned, and the ability of progressing through modelling and simulation is winning opportunity to get over the simple black-box approach, and to aim at systemic innovation.

Moreover, the focus on the reverse logistics dramatically appeared in the recent years. The method innovation, on the contrary, will become permanent requirement. Indeed, the ecoconservativeness is imperative demand, if quality of life continuation is dealt with. This results in sets of accomplishments, with, mainly, two purposes (Michelini, 2010):

- to expand the value chain intangible additions, exploiting ICT means for wealth creation;

- to lower consumption, acting on dumping and pollution, by mandatory recovery.

It shall not be forgot, however, that the EU regulation aims at recovery/reclamation goals, since the European counties are highly inhabited regions, and landfill problems are critical. The enacted bylaws are not specially conservative in terms of energy balance, because of the mandatory targets do not leave alternatives on exhaustive treatments. The point is object of present discussions, entailing the technical specifications. The method innovation, anyway, looks at the efficiency of the extended enterprise, exploiting fully structured corporations, in lieu of the virtual enterprise, limited to co-operating focused net-concerns (Michelini, 2010), (Michelini \& Razzoli, 2009), (Michelini \& Razzoli, 2010). Of course, such an entrepreneurial achievement effectiveness is highly conditioned by the bureaucratic helpfulness (or lack of efficiency) of each national context (and the recalled ELV case offers significant motivations to rethink the all deregistration course, notably too expensive in Italy).

\section{Conclusions}

To draw conclusions from discussing the topics in sustainable engineering management, the compulsory targets are recognised to establish characterising facts, driven by economic instruments (Hang, 2006), (Knight, 1965):

- the producers responsibility principle, as it surfaces from the EU directives, with regards of the dismissal/ dismantling/recovery requirements;

- the law frame, given by the recover (reuse/recycle) compulsory targets, as economic instruments for process effectiveness with return on investment;

- the example regulation enacted for ELV and WEEE, by free-take-back, grounded on recycling visible-fees and design-for-dismantling/recovering rules; 
- the operation set-ups, leading to enhanced usability and reverse logistics achievements, for environment protection and eco-sustainability.

The economic instruments are, moreover, starting aids for method innovation promoting knowledge-driven entrepreneurship. In that context, the ambient intelligence as noteworthy option to enrich the product-service delivery, (Michelini \& Razzoli, 2008), (Michelini \& Razzoli, 2008b), supported by extended enterprise organisations, explicitly warranting the producers' responsibility principle, expanded to cover on-duty and end-of-life operations, including eco-footprint control and conformance-to-use checks. The ambient intelligence provides ubiquitous computing and communication aids, to fulfil the monitoring and vaulting duties, already, required by the EU environmental policy by compulsory recovery and reclamation targets, fixed for mass-product durables, such as, ELV or WEEE.

The same class of ICT aids are winning opportunity, for restructuring the supply chain by information intensive deliveries, to avoid or, at least, drastically lower polluting emissions and wreck dumping, and to provide adequate recording of resource consumption. On these grounds, ambient intelligence tools acquire quite special flavour, since they are invoked to face very demanding incumbents, with resort to the frameworks of the reverse logistics in the knowledge society issues. The suitable choice of fitting economic instruments is critical premise, to permit efficient opening out of the reverse logistics treatment from the today limited cases of durables, to the more pervasive situations of the disposables. The question is totally open, but the eco-policy cannot reach balanced achievements, unless the totality of the tangible goods undergo suited remediation.

\section{References}

Abe, J.M.; Dempsey, P.E. \& Basset, D.A. (1998). Business ecology: giving your organisation the natural edge, Butterworth-Heinemann, London.

Acaccia, G.M.; Michelini, R.C. \& Qualich, N. (2005). End-of-life vehicles collection and disassembly: modelling and simulation, Joint ESM-MESM Conf., EUROSIS 05, pp. 34-40, Porto, Oct. 24-26.

Acaccia, G.M.; Michelini, R.C.; Penzo, L. \& Qualich, N. (2006a). Modelling and simulation of car dismantling facilities, Joint ECEC \& FUBUTEC Intl. Conf., pp. 70-75, Athens, Apr. 17-19, ISBN 9077381244

Acaccia, G.M.; Michelini, R.C. \& Qualich, N. (2006b). End-of-life vehicles models with recycling in mind, Joint ECEC \& FUBUTEC Intl. Conf., pp. 76-82, Athens, Apr. 17-19, ISBN 9077381244.

ARN (2008). ARN Sustainability Report 2008, Auto Recycling Nederland, www.arn.nl

Blumberg, D.F. (2004). Introduction to management of reverse logistics and closed loop supply chain processes, D.F. Blumberg Associates, CRC Press, p. 296.

BMW Group (2004). Innovation, efficiency, responsibility: sustainable value report 2003/2004, Brand: BMW, Rolls-Royce Motor Cars Limited, MINI.

CEN/TC 273 WG4 (1999). Logistics performance measures requirements and measuring methods, Report BT N 5976, 19 November 1999.

Dekker, R.; Fleischmann, M.; Inderfurth, K. \& van Wassenhove, L.N., Eds. (2004). Reverse logistics: quantitative models for closed loop supply chains, Springer, p. 436.

Dyckhoff, H.; Lackes, R. \& Reese, J., Eds. (2004). 'Supply chain management and reverse logistics, Springer, p. 426. 
European Commission, (2006): http:/ / ec.europa.eu/environment/waste/index.htm.

Freedman, M. \& Jaggi, B., Eds. (2006). Advances in environmental accounting, Emerald Book, London.

Hang, W. (2006). Chances and limits of design-for-recycling: view on current developments, 6th Intl. Automobile Recycling Congress, Amsterdam, March 15-17.

Kahraman, E. \& Baig, A., Eds. (2009). Environmentalism: environmental strategies and environment sustainability, Nova Sci. Pub., New York.

Knight, G.B. (1965). Basic concepts of ecology, Macmillan, New York.

Lapide, L., (2005). Proceeding of the supply chain 2020 project's industry advisory council, March 17, MIT Centre for Transportation and Logistics.

Larson, B.A., Ed. (2009). Sustainable development research advances, Nova Sci. Pub., New York.

Leavis, F.R. \& Thompson, D. (1993). Culture and environment: the training of critical awareness, Chatto \& Windus, London.

Loeffe, C.V., Ed. (2009). Conservation and recycling of resources: new research, Nova Sci. Pub., New York.

Meijer, D. \& DeJong, F., Eds. (2009). Environmental regulation, evaluation, compliance and economic impact, Nova Sci. Pub., New York.

Michelini, R.C. (2009). Robot age knowledge changeover, Nova Sci. Pub., New York.

Michelini, R.C. (2010). Knowledge society engineering: the sustainable growth pledge, Nova Sci. Pub., New York.

Michelini, R.C.; Acaccia, G.M. \& Molfino, R.M. (2002) Simulation and intelligent automation: activity at the industrial robot design research laboratory, Modeling $\mathcal{E}$ Simulation Magazine, Vol. 1, No. 2, pp. 6-7.

Michelini, R.C.; Acaccia, G.M.; Callegari, M.; Molfino, R.M. \& Razzoli, R.P. (2001). Computer integrated assembly for cost effective development, In: C.T. Leondes Ed.: Computer Integrated Manufacturing, Vol. II, CRC Press LLC, Boca Raton (FL), pp. 2.01-2.68.

Michelini, R.C.; Acaccia, G.M.; Callegari, M.; Molfino, R.M. \& Razzoli R.P. (1997). Shop controller-and-manager for intelligent manufacturing, In: S. Tzafestas Ed.: Management and Control of Manufacturing Systems, Springer, London, pp. 219-254.

Michelini, R.C. \& Coiffet, P. (2010). Essai sur les capitaux assurant la fortune de l'humanité, Académie de France des Technologies, Paris, Librairie: http://www.academietechnologies.fr.

Michelini, R.C. \& Kovàcs, G.L. (2002). Integrated design for sustainability: intelligence for eco-consistent products-and-services, The Estonian Business School Review, Tallin, Winter 2002-3 issue, No. 15, Dec., pp. 81-95.

Michelini, R.C. \& Razzoli, R.P. (2000). Affidabilità e sicurezza del manufatto industriale: progetto per lo sviluppo sostenibile, Tecniche Nuove, Milano, p. 300, ISBN 88-481-1085 I.

Michelini, R.C. \& Razzoli, R.P. (2004). Product-service for environmental safeguard: a metric to sustainability, Intl. J. Resources, Conservation and Recycling, Vol. 42, No. 1, August, pp. 83-98.

Michelini, R.C. \& Razzoli, R.P. (2004b). Product-service eco-design: knowledge-based infrastructures, Intl. J. Cleaner Production, Elsevier, Vol. 12, No. 4, May, pp. 415-428.

Michelini, R.C. \& Razzoli, R.P. (2005). Collaborative networked organisations for ecoconsistent supply-chains, In: Virtual Enterprise Integration: Technological and Organisational Perspectives, G.D. Putnik, M.M. Cunha (Eds.), IDEA Group, IGI Press, Hershey, PA, pp. 45-77. 
Michelini, R.C. \& Razzoli, R.P. (2008). Innovation for sustainability in product lifecycle design, In: Computer-Aided Innovation, G. Cascini (Ed.), Springer, Boston, pp. 217228, ISBN 978-0-387-09696-4.

Michelini, R.C. \& Razzoli, R.P. (2008b). Ubiquitous computing \& communication for product monitoring, In: M. Khosrow-Pour, Ed., Encyclopaedia of Information Science $\mathcal{E}$ Technology, 2nd Ed., IDEA Group Inc., 2008, pp. 3851-3857, ISBN 978-1-60566-026-4.

Michelini, R.C. \& Razzoli, R.P. (2009). The service net facility integration appraisal, Intl. J. Services, Economics and Management, No. 4, pp. 371-392, ISSN: 1753-0822.

Michelini, R.C. \& Razzoli, R.P. (2010). Environment-enterprise integration: networked entrepreneurial opportunities, In: F. Teuteberg \& J.M. Gomez, Eds., Corporate Environmental Management Information Systems, IDEA Group Inc., Hershey (PA).

Mihailovich, D.T. \& Lalic, B. Eds. (2009). Advances in environmental modelling and measurements, Nova Sci. Pub., New York.

Morin, P.J. (1999). Community ecology, Blackwell Scientific, New York.

Muñoz, S.I., Ed. (2009). Ecology research progress, Nova Sci. Pub., New York.

Naess, A. (1989). Ecology, community and lifestyle: an eco-sophy outline, Cambridge Univ. Press, Cambridge.

O'Neill, J. (2001). Ecology, policy and politics, Cambridge Univ. Press, London.

Paul, R.T. (2006). Recyclability of selected vehicles in North America, 6th Intl. Automobile Recycling Congress, Amsterdam, March 15-17.

Pertsova, C.C., Ed. (2008). Ecological economics research trends, Nova Sci. Pub., New York.

Popov, F. \& DeSimone, F.D. (1997). Eco-efficiency: the business link to sustainable development, The MIT Press, Cambridge.

Sakao, T. \& Lindhal, M. (2009). Introduction to product-service systems design, Springer Verlag, Berlin, ISSN 978-1-84882-908-4.

Scarpa, R. \& Alberini, A.A. (2005). Application of simulation in environment and resource economics, Springer, London.

Schoensleben, P. (2004). Integral logistics management: planning and control of comprehensive supply chains, 2 ed., CRC Press, Boca Raton.

Schmidt, M.; Joao, E. \& Albrecht, E., Eds. (2005). Implementing strategic environment assessment, Springer, London.

Sperling, D. (2009). Two billions of cars, Oxford Uni. Press, Oxford.

Stark, J. (2005). Product lifecycle management, Springer, London.

Suhas, H.K. (2001). From quality to virtual enterprise: an integrated approach, CRC Press, Boca Raton.

Uchitelle, L. (2006). The disposable America: layoffs and their consequences, Knopf, New York.

Veleva, V. \& Ellenbecker, M. (1996). Ecological design, Inland Press, Washington.

Wackernagel, M. \& Rees, W. (1995). Our ecological footprint: reducing human impact on the earth, New Society Pub., Gabriola Inland.

Weizsäcker, E.V.; Lovins, A.B. \& Lovins, L.H. (1997). Factor four: doubling wealth, halving resource use, The new Report to the Club of Rome, Earthscan Pub. Ltd., London. 


\section{Discrete Event}

Simulations

edined by Mar cout

\section{Discrete Event Simulations}

Edited by Aitor Goti
ISBN 978-953-307-115-2

Hard cover, 330 pages

Publisher Sciyo

Published online 18, August, 2010

Published in print edition August, 2010

Considered by many authors as a technique for modelling stochastic, dynamic and discretely evolving systems, this technique has gained widespread acceptance among the practitioners who want to represent and improve complex systems. Since DES is a technique applied in incredibly different areas, this book reflects many different points of view about DES, thus, all authors describe how it is understood and applied within their context of work, providing an extensive understanding of what DES is. It can be said that the name of the book itself reflects the plurality that these points of view represent. The book embraces a number of topics covering theory, methods and applications to a wide range of sectors and problem areas that have been categorised into five groups. As well as the previously explained variety of points of view concerning DES, there is one additional thing to remark about this book: its richness when talking about actual data or actual data based analysis. When most academic areas are lacking application cases, roughly the half part of the chapters included in this book deal with actual problems or at least are based on actual data. Thus, the editor firmly believes that this book will be interesting for both beginners and practitioners in the area of DES.

\section{How to reference}

In order to correctly reference this scholarly work, feel free to copy and paste the following:

Rinaldo Michelini and Roberto Razzoli (2010). Reverse Logistics: End-of-Life Recovery Pledge, Discrete Event Simulations, Aitor Goti (Ed.), ISBN: 978-953-307-115-2, InTech, Available from:

http://www.intechopen.com/books/discrete-event-simulations/reverse-logistics-end-of-life-recovery-pledge

\section{INTECH}

open science | open minds

\section{InTech Europe}

University Campus STeP Ri

Slavka Krautzeka 83/A

51000 Rijeka, Croatia

Phone: +385 (51) 770447

Fax: +385 (51) 686166

www.intechopen.com

\section{InTech China}

Unit 405, Office Block, Hotel Equatorial Shanghai

No.65, Yan An Road (West), Shanghai, 200040, China

中国上海市延安西路65号上海国际贵都大饭店办公楼 405 单元

Phone: +86-21-62489820

Fax: $+86-21-62489821$ 
(C) 2010 The Author(s). Licensee IntechOpen. This chapter is distributed under the terms of the Creative Commons Attribution-NonCommercialShareAlike-3.0 License, which permits use, distribution and reproduction for non-commercial purposes, provided the original is properly cited and derivative works building on this content are distributed under the same license. 